\title{
Optimization of culture conditions to produce high yields of active Acetobacter sp. CCTCC M209061 cells for anti-Prelog reduction of prochiral ketones
}

\author{
Xiao-Hong Chen ${ }^{1}$, Wen-Yong Lou ${ }^{1 *}$, Min-Hua Zong ${ }^{2^{*}}$ and Thomas J Smith ${ }^{3^{*}}$
}

\begin{abstract}
Background: Chiral alcohols are widely used in the synthesis of chiral pharmaceuticals, flavors and functional materials and appropriate whole-cell biocatalysts offer a highly enantioselective, minimally polluting route to these valuable compounds. The recently isolated strain Acetobacter sp. CCTCC M209061 showed exclusive anti-Prelog stereoselectivity for the reduction of prochiral ketones, but the low biomass has limited its commercialization and industrial applications. To tackle this problem, the effects of medium components and culture conditions on the strain's growth and reduction activity were explored.
\end{abstract}

Results: By using a one-at-a-time method and a central composite rotatable design (CCRD), the optimal medium and culture conditions were found to be as follows: glucose $8.26 \mathrm{~g} / \mathrm{L}$, fructose $2.50 \mathrm{~g} / \mathrm{L}$, soy peptone $83.92 \mathrm{~g} / \mathrm{L}$, $\mathrm{MnSO}_{4} \cdot \mathrm{H}_{2} \mathrm{O} 0.088 \mathrm{~g} / \mathrm{L}, \mathrm{pH} 5.70,30^{\circ} \mathrm{C}$ and $10 \%(\mathrm{v} / \mathrm{v})$ inoculum. Under the above-mentioned conditions, the biomass after $30 \mathrm{~h}$ cultivation reached $1.10 \pm 0.03 \mathrm{~g} / \mathrm{L}$, which was 9.5-fold higher than that obtained with basic medium. Also, the reduction activity towards 4'-chloroacetophenone was markedly enhanced to $39.49 \pm 0.96 \mu \mathrm{mol} / \mathrm{min} / \mathrm{g}$ from $29.34 \pm 0.65 \mu \mathrm{mol} / \mathrm{min} / \mathrm{g}$, with the product e.e. being above 99\%. Comparable improvements were also seen with the enantioselective bioreduction of 4-(trimethylsilyl)-3-butyn-2-one to the key pharmaceutical precursor $(R)$ 4-(trimethylsilyl)-3-butyn-2-ol.

Conclusions: The biomass and reduction activity of Acetobacter sp. CCTCC M209061 can be greatly enhanced through the optimization strategy. This facilitates use of the strain in the anti-Prelog stereoselective reduction of prochiral ketones to enantiopure chiral alcohols as building blocks for many industries.

\section{Background}

Acetobacter is a genus of acetic acid bacteria characterized by the ability to convert ethanol to acetic acid in the presence of oxygen. Acetobacter sp. is widely used in various fields of biotechnology [1]. The longest-established applications of this genus are the strains used for producing vinegar by oxidation of ethanol to acetic acid [2]. In addition, bacterial cellulose produced by

\footnotetext{
* Correspondence: wylou@scut.edu.cn; btmhzong@scut.edu.cn; t.j.smith@shu. ac.uk

'Lab of Applied Biocatalysis, South China University of Technology, Guangzhou, 510640, China

${ }^{2}$ College of Light Industry and Food Sciences, South China University of Technology, Guangzhou, 510640, China

Full list of author information is available at the end of the article
}

Acetobacter xylinum has attracted attention because of its unique physical and mechanical properties such as its existence as pure cellulose aggregate, high crystallinity, high biocompatibility, and hence its promising properties for application in composite membranes [3], medical materials [4], electronic paper [5] and fuel cells [6]. Strains of Acetobacter have also proven to be efficient biocatalysts for the enantioselective oxidation of various alcohols to yield optically pure carboxylic acids. For example, Molinari et al. studied the oxidation of 2phenylpropanol with Acetobacter aceti [7], prochiral 2methyl-1, 3-propandiol by Acetobacter pasteurianus [8], and polyconjugated compounds catalyzed by Acetobacter aceti [9]. However, there have been only a few studies of the application of Acetobacter for asymmetric reduction 
of prochiral ketones. A novel strain, Acetobacter sp. CCTCC M209061, reported in our previous paper [10], isolated from Chinese kefir grains, showed exclusive anti-Prelog stereoselectivity for the reduction of 4-(trimethylsilyl)-3-butyn-2-one to (R)-4-(trimethylsilyl)-3butyn-2-ol, which is a key chiral intermediate for the synthesis of $(R)$-benzyl-4-hydroxyl-2-pentynoate, a molecule that has potential therapeutic function for Alzheimer's disease. Also, Acetobacter sp. CCTCC M209061 effectively catalyzed asymmetric reduction of a series of prochiral aryl ketones and hence may be suitable for synthesis of valuable chiral alcohols. Whilst the substrate range and enantioselectivity of Acetobacter sp. CCTCC M209061 are promising and have enabled a biotransformation that has not been effectively accomplished with other strains, the low biomass density produced by cultures of this strain is a limitation for its application and commercialization. For example, the twelve strains of acetic acid bacteria investigated previously by Romano et al. for use in enantioselective biocatalysis gave average culture biomass densities between 1.0 to $4.4 \mathrm{~g} / \mathrm{L}$ (dry weight [dw]) [11]. In contrast, Acetobacter sp. CCTCC M209061 yielded much less biomass in basic medium $(0.11 \mathrm{~g} / \mathrm{L} \mathrm{dw})$ and tomato juice medium $(0.34 \mathrm{~g} / \mathrm{L} \mathrm{dw})$. Previous reports in the literature have shown that culture conditions can greatly influence alcohol dehydrogenase (ADH) activities from acetic acid bacteria such as Acetobacter sp. [12] and Gluconobacter oxydans [13]. Thus, the current study was undertaken with the aim of more thoroughly exploring the growth medium composition and culture conditions to improve growth and reduction activity of the novel strain Acetobacter sp. CCTCC M209061 toward practical applications.

Whilst the classical 'one-factor-at-a-time' method has the severe limitation that it does not allow investigation of interactions between variables, it can be useful under certain circumstances, such as when the primary goal is to attain improvements in performance (rather than necessarily finding the global maximum) and where experimental error is small compared to the effect of the factors under study [14]. Among multivariate optimization methods that can be used more reliably to find global maxima, the response surface methodology (RSM) has previously been shown to be powerful and practicable for program optimization and is often used to identify the relative significance of different factors, interactions between factors and optimal level of test variables. For example, the RSM method was successfully applied to enhance mycelial biomass and polysaccharides produced by Hericium erinaceum [15], biosurfactant produced by Bacillus mycoides [16], protease produced by Bacillus clause [17] and avermectin B1a produced by Streptomyces avermitilis 14-12A [18].
In the present work, the important influential factors affecting the growth and activity of the new strain were initially unknown and so there were a potentially very large number of permutations to study if a multivariate optimization method such as RSM were used from the outset. We therefore began by using a systematic onefactor-at-a-time optimization method to investigate the effects of medium components and culture conditions on the growth and reduction activity of Acetobacter sp. CCTCC M209061. The response surface methodology was then employed, in order to further improve the biomass and the specific activity of the novel strain by more rigorous exploration of the conditions that were indicated as important by the one-factor-at-a-time results. The biocatalytic asymmetric reduction of 4'chloroacetophenone to (R)-1-(4-chlorophenyl) ethanol was employed as a model reaction for evaluating the effects of the various culture condition on the activity of the strain. In addition, the enantioselective reduction of 4-(trimethylsilyl)-3-butyn-2-one to $(R)$-4-(tri-methylsilyl)-3-butyn-2-ol catalyzed by cells in improved media was investigated.

\section{Results and discussion}

\section{Effect of the carbon source}

During the growth of microorganisms, the carbon source in the culture medium plays an important role for the growth of cells, the production of metabolites and the availability of energy to drive endergonic reactions. According to previous studies, the source of carbon for Acetobacter is species and strain dependent. To establish the effect of carbon sources on the growth and reduction activity of Acetobacter sp. CCTCC M209061, the carbohydrates glucose, fructose, galactose, arabinose, ribose, xylose, lactose and sucrose were tested individually as carbon sources (at $10 \mathrm{~g} / \mathrm{L}$ ) in place of the glucose in the basic medium; the control medium was the basic medium with the omission of glucose. The results (Figure 1a) showed that fructose-containing medium gave most abundant cell growth, but lowest reduction activity. In contrast, the glucose-containing medium gave highest specific reduction activity, but relatively poor cell growth. These contrasting effects of carbon source on biomass yield and enzyme activity were consistent with previous studies on Acetobacter strains. In Acetobacter methanolicus and Acetobacter aceti it was found previously that carbon sources which were advantageous to growth did not give best activities of alcohol dehydrogenase $(\mathrm{ADH})$, owing in part to the formation of an inactive form of ADH during growth in certain media [12]. Moreover, addition of glucose influenced the activities of individual components of the electron-transport systems of the aerobic bacteria Azotobacter vinelandii and Acetobacter suboxydans [19], which suggested that 

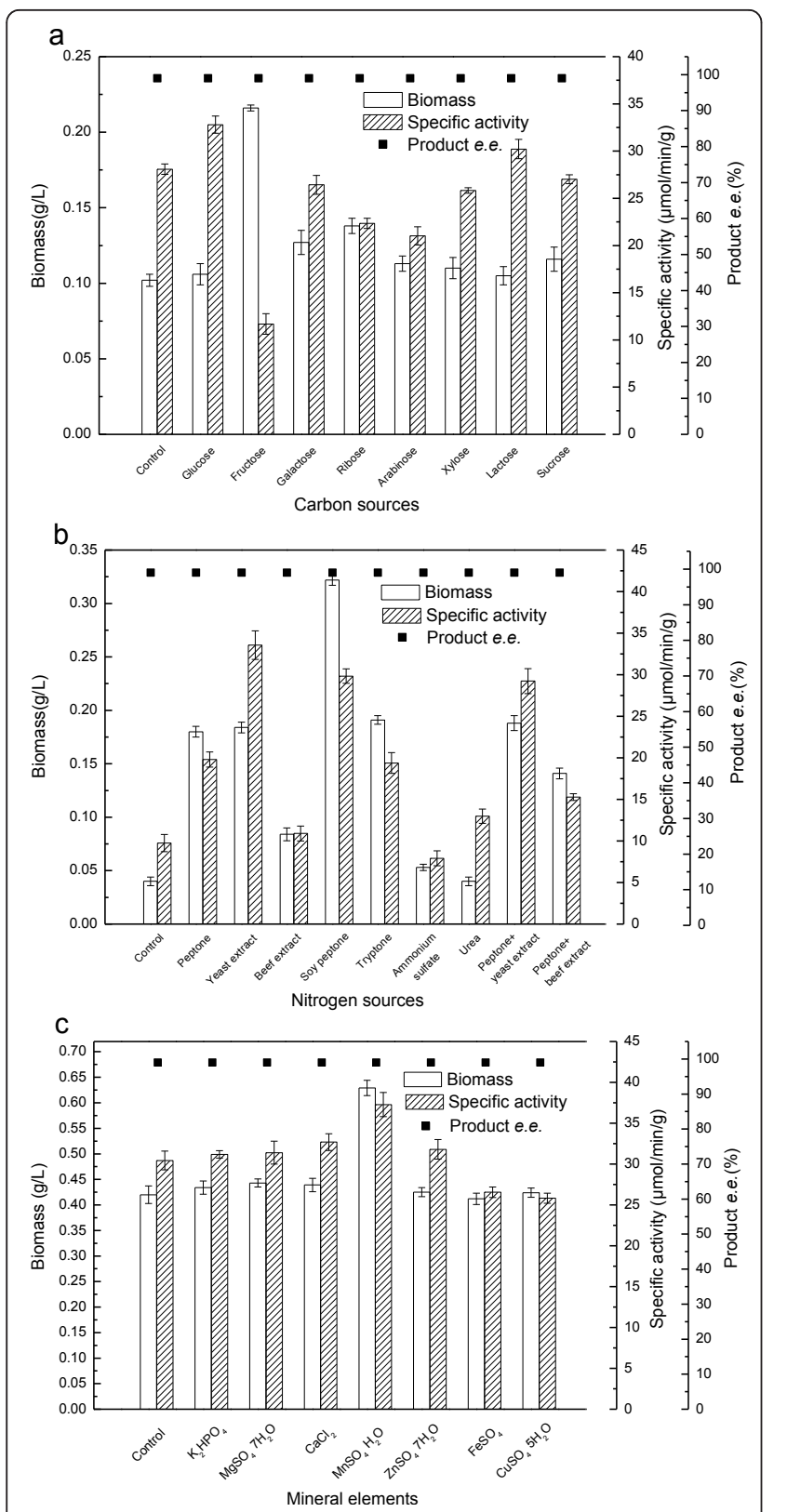

Figure 1 Effect of medium components on cell growth and reduction activity of Acetobacter sp. CCTCC M209061. (a) Effect of carbon sources; (b) Effect of nitrogen sources; (c) Effect of mineral elements. All experimental data are given as the mean \pm SD of triplicate determinations. Control refers to the medium with no added carbon source (a), nitrogen source (b), or mineral element (c) added. The substantial growth observed in the no carbon source control in panel (a) results from the presence of glucose in the seed medium and nitrogen sources (yeast extract and peptone), which can provide a certain amount of carbon. The mixed nitrogen sources investigated in panel (b) contained equal masses of each of two nitrogen sources stated.

carbon source may influence the availability of electron donors for biocatalytic reduction reactions. Since fructose gave best biomass yield and glucose gave best specific reduction activity, media containing mixtures of fructose and glucose were investigated (with fructose: glucose ratios of $10: 0 ; 7.5: 2.5 ; 5: 5 ; 2.5: 7.5$ and $0: 10$, by weight; the total carbon source concentrations were kept at $10 \mathrm{~g} / \mathrm{L}$ ). It was found that the medium containing $7.5 \mathrm{~g} / \mathrm{L}$ glucose and $2.5 \mathrm{~g} / \mathrm{L}$ fructose gave the best combination of cell growth $(0.20 \pm 0.01 \mathrm{~g} / \mathrm{L})$ and reduction activity $(29.14 \pm 0.83 \mu \mathrm{mol} / \mathrm{min} / \mathrm{g})$.

\section{Effect of nitrogen source}

Various organic and inorganic nitrogen sources ( $2.15 \mathrm{~g} /$ $\mathrm{L}$ calculated as nitrogen) were also examined for their effects on growth and reduction activity in place of the peptone and yeast extract in the basic medium (Figure 1b). Cells grown in the medium containing soy peptone as nitrogen source produced the largest amount of biomass. Indeed, soy peptone is a complex ingredient which contains several essential amino acids as well as many other growth-promoting factors and it is known that its addition can have a positive influence on biomass production [20]. Lower biomasses were observed in culture media containing other complex nitrogen sources (peptone, yeast extract and tryptone) and the Acetobacter sp. CCTCC M209061 grew very little in media with ammonium sulfate or urea as the nitrogen source, or in the control medium without the addition of a nitrogen source.

Of all the nitrogen sources tested, the highest reduction activity was obtained with yeast extract. High reduction activities were also obtained in media with soy peptone and a mixture of peptone and yeast extract. The other organic and inorganic nitrogen sources gave substantially lower reduction activities and were judged unsuitable for producing highly active biocatalyst. Mixtures of soy peptone and yeast extract (the ratios were $1: 0 ; 3: 1 ; 1: 1 ; 1: 3$ and $0: 1$, total nitrogen concentration held at $2.15 \mathrm{~g} / \mathrm{L}$ ) were also tested as nitrogen source, but the result was no better than soy peptone alone $(26.9 \mathrm{~g} / \mathrm{L})$, therefore, soy peptone (which gave the best combination of biomass yield and specific reduction activity) was chosen as the nitrogen source for subsequent experiments. The effects of different concentrations of soy peptone $(40-80 \mathrm{~g} / \mathrm{L})$ were also investigated. Biomass and specific activity were improved with the increase of concentration, but higher than $70 \mathrm{~g} / \mathrm{L}$ gave negligible improvement and so a concentration of soy peptone of $70 \mathrm{~g} / \mathrm{L}$ was selected for further study which gave a high cell growth $(0.32 \pm 0.01 \mathrm{~g} / \mathrm{L})$ and reduction activity $(29.83 \pm 0.87 \mu \mathrm{mol} / \mathrm{min} / \mathrm{g})$.

\section{Effect of mineral element}

Seven mineral elements (potassium, magnesium, calcium, zinc, manganese, ferrous and copper ions) were chosen for investigation as medium additives based on their known roles in bacterial metabolism and as 
cofactors for metabolic enzymes [21,22]. Addition of the various mineral elements to the culture medium was investigated by adding the salts $\mathrm{K}_{2} \mathrm{HPO}_{4}, \mathrm{MgSO}_{4} \cdot 7 \mathrm{H}_{2} \mathrm{O}$, $\mathrm{CaCl}_{2}, \quad \mathrm{MnSO}_{4} \cdot \mathrm{H}_{2} \mathrm{O}, \quad \mathrm{ZnSO}_{4} \cdot 7 \mathrm{H}_{2} \mathrm{O}, \quad \mathrm{FeSO}_{4}$ and $\mathrm{CuSO}_{4} \cdot 5 \mathrm{H}_{2} \mathrm{O}$ to separate aliquots of media to concentrations of 2.0, 1.0, 1.0, 0.05, 0.02, 0.003 and $0.005 \mathrm{~g} / \mathrm{L}$, respectively, in place of the $\mathrm{K}_{2} \mathrm{HPO}_{4}$ in the basic medium. These concentrations were selected based on the requirement for these elements for the growth of microorganisms in previous studies, and to keep their concentrations below expected inhibitory levels [23]. Most of the minerals did not have a substantial effect on yields of biomass or reduction activity (Figure 1c); however, $\mathrm{Mn}^{2+}$ improved the growth and reduction activity by extending the logarithmic growth phase. It has been reported previously that manganese is an important component of tomato juice when used for the cultivation of microorganisms [24], which was consistent with our result and suggested that supplementation with manganese may be an alternative to addition of tomato juice to the medium for cultivation of Acetobacter sp. CCTCC M209061. The addition of $\mathrm{K}, \mathrm{Mg}, \mathrm{Ca}$ and $\mathrm{Zn}$ ions has been found to improve cell growth and product yields in other studies $[25,15]$ but afforded negligible benefits here, presumably because none of these minerals was limiting for cell growth or reduction activity. Fe and $\mathrm{Cu}$ ions slightly inhibited reduction activity, which may be due to their relatively high concentrations for this strain. To determine the effect of $\mathrm{Mn}^{2+}$ concentration on the biomass and reduction activity of Acetobacter sp. CCTCC M209061, different concentrations of $\mathrm{MnSO}_{4} \cdot \mathrm{H}_{2} \mathrm{O}$ ranging from 0 to $0.10 \mathrm{~g} / \mathrm{L}$ were added to the medium. A manganese concentration of $0.075 \mathrm{~g} / \mathrm{L}$ gave a maximum biomass yield of $0.94 \pm 0.04 \mathrm{~g} / \mathrm{L}$ and a maximum specific reduction activity of $34.15 \pm 1.05$ $\mu \mathrm{mol} / \mathrm{min} / \mathrm{g}$.

\section{Effects of extra vitamins}

Vitamins play a key role for many microorganisms because they act as coenzymes or precursors of coenzymes [26]; they are therefore often crucial for cell growth and enzyme activities at very small concentrations. Indeed, complex nutrient sources such as soy peptone contain certain vitamins at small concentrations, so it is possible that part of the beneficial effect of adding such preparations to the medium was because they were supplying vitamin(s). To investigate the effect of vitamins specifically, the following vitamins were added to the medium: thiamine (vitamin B1), nicotinic acid (vitamin B3), pyridoxine (vitamin B6) and ascorbic acid (vitamin C), biotin (vitamin $\mathrm{H}$ or B7), each at a concentration of $2.0 \mathrm{mg} / \mathrm{L}$. However, none of the vitamins examined produced notable differences from the control without added vitamins (Table 1). The reason may be
Table 1 Effects of culture factors on cell growth and reduction activity of Acetobacter sp. CCTCC M209061

\begin{tabular}{|c|c|c|c|}
\hline Factor & $\begin{array}{c}\text { Biomass } \\
(\mathrm{g} / \mathrm{L})\end{array}$ & $\begin{array}{c}\text { Specific activity } \\
(\mu \mathrm{mol} / \mathrm{min} / \mathrm{g})\end{array}$ & e.e. (\%) \\
\hline \multicolumn{4}{|l|}{ Extra vitamins } \\
\hline Control & $0.94 \pm 0.04$ & $34.15 \pm 1.05$ & $\geq 99$ \\
\hline Vitamin B1 & $0.93 \pm 0.03$ & $34.36 \pm 0.94$ & $\geq 99$ \\
\hline Nicotinic acid & $0.93 \pm 0.01$ & $35.04 \pm 1.07$ & $\geq 99$ \\
\hline Pyridoxine & $0.95 \pm 0.02$ & $34.18 \pm 0.89$ & $\geq 99$ \\
\hline Ascorbic acid & $0.94 \pm 0.03$ & $33.88 \pm 0.93$ & $\geq 99$ \\
\hline Biotin & $0.93 \pm 0.04$ & $34.59 \pm 0.86$ & $\geq 99$ \\
\hline \multicolumn{4}{|l|}{$\mathrm{pH}$} \\
\hline 4 & $0.38 \pm 0.01$ & $11.61 \pm 0.39$ & $\geq 99$ \\
\hline 5 & $0.95 \pm 0.02$ & $34.67 \pm 1.10$ & $\geq 99$ \\
\hline 6 & $0.94 \pm 0.04$ & $34.15 \pm 1.05$ & $\geq 99$ \\
\hline 7 & $0.82 \pm 0.03$ & $29.37 \pm 0.84$ & $\geq 99$ \\
\hline 8 & $0.48 \pm 0.01$ & $23.03 \pm 0.58$ & $\geq 99$ \\
\hline \multicolumn{4}{|l|}{ Temperature $\left({ }^{\circ} \mathrm{C}\right)$} \\
\hline 25 & $0.79 \pm 0.03$ & $33.01 \pm 1.10$ & $\geq 99$ \\
\hline 30 & $0.95 \pm 0.02$ & $34.67 \pm 1.10$ & $\geq 99$ \\
\hline 35 & $0.86 \pm 0.02$ & $31.38 \pm 1.05$ & $\geq 99$ \\
\hline 40 & $0.62 \pm 0.02$ & $23.21 \pm 0.61$ & $\geq 99$ \\
\hline 45 & $0.08 \pm 0.01$ & 0 & - \\
\hline \multicolumn{4}{|c|}{ Shaking rate (rpm) } \\
\hline 40 & $0.76 \pm 0.02$ & $39.55 \pm 1.12$ & $\geq 99$ \\
\hline 80 & $0.96 \pm 0.02$ & $36.76 \pm 1.03$ & $\geq 99$ \\
\hline 100 & $0.95 \pm 0.02$ & $34.67 \pm 1.10$ & $\geq 99$ \\
\hline 120 & $0.97 \pm 0.02$ & $30.14 \pm 0.99$ & $\geq 99$ \\
\hline 160 & $0.96 \pm 0.03$ & $24.24 \pm 0.65$ & $\geq 99$ \\
\hline 200 & $0.97 \pm 0.04$ & $17.74 \pm 0.47$ & $\geq 99$ \\
\hline
\end{tabular}

that such vitamins that the culture required were already present in the soy peptone component of the medium.

\section{Effects of the initial $\mathrm{pH}$}

The $\mathrm{pH}$ value of culture medium can affect the functions of the cell membrane, the cell structure, the uptake of various nutritional sources, and the biosynthesis of metabolites [27]. The effects of the initial $\mathrm{pH}$ of the culture medium on growth and reduction activity of Acetobacter sp. CCTCC M209061 were studied. The initial $\mathrm{pH} 5$ gave the best combination of cell growth $(0.95 \pm 0.02 \mathrm{~g} / \mathrm{L})$ and reduction activity $(34.67 \pm 1.10 \mu \mathrm{mol} / \mathrm{min} / \mathrm{g})$. Cell growth and reduction activity were inhibited as the $\mathrm{pH}$ increased above 6 and no growth was observed when the initial $\mathrm{pH}$ was $\geq 9$ or $\leq 3$ (Table 1 ). It can be seen that the growth and reduction activity changed very little between $\mathrm{pH}$ 5 and 6, which confirmed a well-established observation that Acetobacter sp. grow best under acidic conditions [28]. 
Effects of temperature and shaking rate

The effects of different culture temperatures and shaking rate were also investigated; the optimum growth and reduction activity were gained at $30^{\circ} \mathrm{C}$ and $80 \mathrm{rpm}$ (Table 1). The biomass yield and specific reduction activity were $0.96 \pm 0.02 \mathrm{~g} / \mathrm{L}$ and $36.76 \pm 1.03 \mu \mathrm{mol} /$ $\mathrm{min} / \mathrm{g}$ respectively at the conditions optimized by the one-at-a-time method.

\section{Optimization by response surface methodology}

As detailed above, RSM is a useful and practicable method among different multivariate optimization methods. Based on the results obtained from the one-factorat-a-time experiments for optimizing the culture medium, the four variables that exhibited greatest effects on cell growth and reduction activity were chosen for CCRD. These were: carbon source, nitrogen source, mineral element and the initial pH. Glucose (supplemented with a fixed concentration of $2.5 \mathrm{~g} / \mathrm{L}$ of fructose in the medium), soy peptone and $\mathrm{Mn}^{2+}$ were selected as the medium components (carbon source, nitrogen source and mineral element, respectively) for further optimization based on the fact that these gave the best reduction activities and biomass yields during the oneat-a-time optimization. In the CCRD experiment the interactions of these medium components were investigated, together with the medium $\mathrm{pH}$.

Table 2 showed the design matrix for the CCRD experiment, together with the experimental results and the predicted responses for growth and reduction activity of Acetobacter sp. CCTCC M209061. The experimental values obtained from the CCRD were regressed by using a quadratic polynomial equation, and the two regression equations, expressed in terms of the coded factors defined in Table 3 were as follows:

$Y_{1}=1.06+0.058 X_{1}-0.010 X_{2}-0.031 X_{3}-0.052 X_{4}+0.022 X_{1} X_{2}-0.020 X_{1} X_{3}+0.0053 X_{1} X_{4}(1)$ $+0.0059 X_{2} X_{3}-0.0016 X_{2} X_{4}-0.0064 X_{3} X_{4}-0.026 X_{1}^{2}-0.016 X_{2}^{2}-0.018 X_{3}^{2}-0.0099 X_{4}^{2}$

$Y_{2}=39.77-1.04 X_{1}+0.94 X_{2}+0.067 X_{3}+2.24 X_{4}-0.44 X_{1} X_{2}+0.72 X_{1} X_{3}+0.13 X_{1} X_{4}(2)$

$-0.26 X_{2} X_{3}-0.16 X_{2} X_{4}+1.30 X_{3} X_{4}-0.90 X_{1}^{2}-0.28 X_{2}^{2}-1.10 X_{3}^{2}-0.15 X_{4}^{2}$

where $Y_{1}$ is the biomass $(\mathrm{g} / \mathrm{L}), Y_{2}$ is the reduction activity $(\mu \mathrm{mol} / \mathrm{min} / \mathrm{g})$, and $X_{1}, X_{2}, X_{3}$ and $X_{4}$ are coded values of the independent variables (glucose; soy peptone; $\mathrm{MnSO}_{4} \cdot \mathrm{H}_{2} \mathrm{O}$ and $\mathrm{pH}$ ). The other culture conditions were as fixed as follows, based on the results from the one-at-a-time optimization: temperature $30^{\circ}$ C, shaking rate $80 \mathrm{rpm}$, inoculum $10 \%(\mathrm{v} / \mathrm{v})$, cultivation time $30 \mathrm{~h}$.

The analysis of variance (ANOVA) for the CCRD experiments was performed (Table 4). The $F$-values and $P$-values were used to identify the effect of each factor on biomass and reduction activity. The models exhibited remarkable correlation with the experimental data with
Table 2 The design and results of the central composite rotatable design (CCRD) experiments

\begin{tabular}{|c|c|c|c|c|c|c|c|c|}
\hline \multirow[t]{2}{*}{ Run } & \multicolumn{4}{|c|}{ Factor } & \multicolumn{2}{|c|}{$\begin{array}{l}\text { Biomass } \\
(\mathrm{g} / \mathrm{L})\end{array}$} & \multicolumn{2}{|c|}{$\begin{array}{l}\text { Specific activity } \\
(\mu \mathrm{mol} / \mathrm{min} / \mathrm{g})\end{array}$} \\
\hline & $\overline{X_{1}}$ & $\mathrm{X}_{2}$ & $x_{3}$ & $\mathrm{X}_{4}$ & Observed & Predicted & Observed & Predicted \\
\hline 1 & -1 & -1 & -1 & -1 & 1.02 & 1.03 & 36.35 & 36.42 \\
\hline 2 & 1 & -1 & -1 & -1 & 1.13 & 1.13 & 33.61 & 33.52 \\
\hline 3 & -1 & 1 & -1 & -1 & 0.96 & 0.95 & 40.03 & 40.02 \\
\hline 4 & 1 & 1 & -1 & -1 & 1.15 & 1.14 & 35.43 & 35.36 \\
\hline 5 & -1 & -1 & 1 & -1 & 1.01 & 1.00 & 32.87 & 33.03 \\
\hline 6 & 1 & -1 & 1 & -1 & 1.03 & 1.03 & 33.12 & 33.02 \\
\hline 7 & -1 & 1 & 1 & -1 & 0.97 & 0.96 & 35.56 & 35.59 \\
\hline 8 & 1 & 1 & 1 & -1 & 1.07 & 1.07 & 34.01 & 33.82 \\
\hline 9 & -1 & -1 & -1 & 1 & 0.92 & 0.93 & 38.35 & 38.36 \\
\hline 10 & 1 & -1 & -1 & 1 & 1.04 & 1.05 & 36.15 & 35.99 \\
\hline 11 & -1 & 1 & -1 & 1 & 0.85 & 0.85 & 41.35 & 41.31 \\
\hline 12 & 1 & 1 & -1 & 1 & 1.05 & 1.06 & 37.50 & 37.17 \\
\hline 13 & -1 & -1 & 1 & 1 & 0.88 & 0.88 & 40.23 & 40.17 \\
\hline 14 & 1 & -1 & 1 & 1 & 0.91 & 0.92 & 40.86 & 40.69 \\
\hline 15 & -1 & 1 & 1 & 1 & 0.82 & 0.82 & 42.16 & 42.07 \\
\hline 16 & 1 & 1 & 1 & 1 & 0.97 & 0.96 & 41.04 & 40.83 \\
\hline $17^{\mathrm{a}}$ & -2 & 0 & 0 & 0 & 0.83 & 0.83 & 38.43 & 38.24 \\
\hline $18^{a}$ & 2 & 0 & 0 & 0 & 1.07 & 1.07 & 33.59 & 34.10 \\
\hline $19^{a}$ & 0 & -2 & 0 & 0 & 1.03 & 1.01 & 36.76 & 36.77 \\
\hline $20^{a}$ & 0 & 2 & 0 & 0 & 0.96 & 0.97 & 40.21 & 40.51 \\
\hline $21^{\mathrm{a}}$ & 0 & 0 & -2 & 0 & 1.06 & 1.05 & 35.09 & 35.25 \\
\hline $22^{\mathrm{a}}$ & 0 & 0 & 2 & 0 & 0.91 & 0.92 & 35.36 & 35.52 \\
\hline $23^{a}$ & 0 & 0 & 0 & -2 & 1.11 & 1.12 & 34.73 & 34.67 \\
\hline $24^{a}$ & 0 & 0 & 0 & 2 & 0.93 & 0.91 & 43.26 & 43.63 \\
\hline $25^{b}$ & 0 & 0 & 0 & 0 & 1.04 & 1.06 & 40.32 & 39.77 \\
\hline $26^{b}$ & 0 & 0 & 0 & 0 & 1.05 & 1.06 & 39.07 & 39.77 \\
\hline $27^{b}$ & 0 & 0 & 0 & 0 & 1.06 & 1.06 & 39.44 & 39.77 \\
\hline $28^{b}$ & 0 & 0 & 0 & 0 & 1.07 & 1.06 & 40.23 & 39.77 \\
\hline $29^{b}$ & 0 & 0 & 0 & 0 & 1.05 & 1.06 & 39.19 & 39.77 \\
\hline $30^{\mathrm{b}}$ & 0 & 0 & 0 & 0 & 1.07 & 1.06 & 40.37 & 39.77 \\
\hline
\end{tabular}

$\mathrm{X}_{1}$, glucose; $\mathrm{X}_{2}$, soy peptone; $\mathrm{X}_{3}, \mathrm{MnSO}_{4} \cdot \mathrm{H}_{2} \mathrm{O} ; \mathrm{X}_{4}$, initial $\mathrm{pH}$.

a Axial point.

${ }^{\mathrm{b}}$ Central point.

very high $F$-values (73.18 and 101.91 for biomass and reduction activity, respectively) and very low $P<0.0001$ for each model, which implied the significance of the two models ( $P$-values less than 0.05 are generally taken to indicate that model terms are significant). By inspection of the

Table 3 Factors and levels in central composite rotatable design (CCRD)

\begin{tabular}{|c|c|c|c|c|c|c|}
\hline \multirow[t]{2}{*}{ Factor } & \multirow[t]{2}{*}{ Name } & \multicolumn{5}{|c|}{ Coded level } \\
\hline & & -2 & -1 & 0 & 1 & 2 \\
\hline$X_{1}$ & Glucose $(g / L)$ & 2.5 & 5 & 7.5 & 10 & 12.5 \\
\hline$x_{2}$ & Soy peptone (g/L) & 60 & 70 & 80 & 90 & 100 \\
\hline$x_{3}$ & $\mathrm{MnSO}_{4} \cdot \mathrm{H}_{2} \mathrm{O}(\mathrm{g} / \mathrm{L})$ & 0.07 & 0.08 & 0.09 & 0.10 & 0.11 \\
\hline$X_{4}$ & $\mathrm{pH}$ & 4.5 & 5 & 5.5 & 6 & 6.5 \\
\hline
\end{tabular}


Table 4 Analysis of variance (ANOVA) for the experimental results of the CCRD

\begin{tabular}{|c|c|c|c|c|c|c|c|c|c|c|}
\hline \multirow[t]{2}{*}{ Source } & \multicolumn{5}{|c|}{ Biomass (g/L) } & \multicolumn{5}{|c|}{ Specific activity $(\mu \mathrm{mol} / \mathrm{min} / \mathrm{g})$} \\
\hline & SS & df & SM & $F$-value & $P$-value* & SS & df & SM & $F$-value & $P$-value \\
\hline Model & 0.22 & 14 & 0.015 & 73.18 & $<0.0001$ & 256.26 & 14 & 18.30 & 101.9 & $<0.0001$ \\
\hline$x_{1}$ & 0.081 & 1 & 0.081 & 384.8 & $<0.0001$ & 25.74 & 1 & 25.74 & 143.3 & $<0.0001$ \\
\hline$x_{2}$ & 0.0024 & 1 & 0.0024 & 11.30 & 0.0043 & 20.99 & 1 & 20.99 & 116.8 & $<0.0001$ \\
\hline$x_{3}$ & 0.024 & 1 & 0.024 & 112.7 & $<0.0001$ & 0.11 & 1 & 0.11 & 0.6066 & 0.4482 \\
\hline$x_{4}$ & 0.065 & 1 & 0.065 & 307.5 & $<0.0001$ & 120.26 & 1 & 120.26 & 669.5 & $<0.0001$ \\
\hline$x_{1} x_{2}$ & 0.0079 & 1 & 0.0079 & 37.38 & $<0.0001$ & 3.11 & 1 & 3.11 & 17.33 & 0.0008 \\
\hline$x_{1} x_{3}$ & 0.0062 & 1 & 0.0062 & 29.43 & $<0.0001$ & 8.40 & 1 & 8.40 & 46.80 & $<0.0001$ \\
\hline$X_{1} X_{4}$ & 0.00045 & 1 & 0.00045 & 2.143 & 0.1638 & 0.28 & 1 & 0.28 & 1.539 & 0.2338 \\
\hline$x_{2} x_{3}$ & 0.00056 & 1 & 0.00056 & 2.677 & 0.1226 & 1.08 & 1 & 1.08 & 6.031 & 0.0267 \\
\hline$x_{2} x_{4}$ & 0.00004 & 1 & 0.00004 & 0.1850 & 0.6729 & 0.43 & 1 & 0.43 & 2.383 & 0.1435 \\
\hline$x_{3} x_{4}$ & 0.00066 & 1 & 0.00066 & 3.147 & 0.0964 & 27.03 & 1 & 27.03 & 150.5 & $<0.0001$ \\
\hline$x_{1}^{2}$ & 0.019 & 1 & 0.019 & 91.35 & $<0.0001$ & 22.26 & 1 & 22.26 & 123.9 & $<0.0001$ \\
\hline$x_{2}^{2}$ & 0.0068 & 1 & 0.0068 & 32.25 & $<0.0001$ & 2.18 & 1 & 2.18 & 12.15 & 0.0033 \\
\hline$x_{3}^{2}$ & 0.0088 & 1 & 0.0088 & 41.55 & $<0.0001$ & 33.01 & 1 & 33.01 & 183.8 & $<0.0001$ \\
\hline$x_{4}^{2}$ & 0.0027 & 1 & 0.0027 & 12.67 & 0.0029 & 0.68 & 1 & 0.66 & 3.648 & 0.0755 \\
\hline \multirow[t]{2}{*}{ Lack of fit } & 0.0025 & 10 & 0.00025 & 1.89 & 0.2497 & 0.88 & 10 & 0.088 & 0.24 & 0.9722 \\
\hline & \multicolumn{4}{|c|}{$R^{2}=0.9856$} & & \multicolumn{5}{|c|}{$R^{2}=0.9896$} \\
\hline
\end{tabular}

$\mathrm{X}_{1}$, glucose; $\mathrm{X}_{2}$, soy peptone; $\mathrm{X}_{3}, \mathrm{MnSO}_{4} \cdot \mathrm{H}_{2} \mathrm{O} ; \mathrm{X}_{4}$, initial $\mathrm{pH}$.

${ }^{*} \mathrm{P}<0.05$ are significant.

SS: Sum of squares; DF: degrees of freedom; SM: mean squares.

$F$ - and $P$-values of each factor, it can be seen that glucose had the largest effect on biomass, followed by $\mathrm{pH}$, $\mathrm{MnSO}_{4} \cdot \mathrm{H}_{2} \mathrm{O}$ and soy peptone. The order of effects on reduction activity was $\mathrm{pH}>$ glucose $>$ soy peptone. Within the examined concentration range (0.07-0.11 g/L), change of $\mathrm{MnSO}_{4} \cdot \mathrm{H}_{2} \mathrm{O}$ concentration showed only slight impact on the reduction activity. It is noteworthy that the variable that had greatest influence on the production of biomass (glucose concentration) was different from that which exerted most significant impact on the reduction activity ( $\mathrm{pH}$ of the medium). It is well known that the metabolic networks of microorganisms are very complicated and respond in a complex manner to environmental conditions. Here, the balance of these factors clearly resulted in a different response of reduction activity and cellular growth to the various culture conditions explored. It is possible that glucose concentration had greatest effect upon accumulation of biomass because cellular growth was limited to a large extent by the availability of glucose as the principal carbon and energy source of the cells. whilst there were many possible explanations of the large influence of medium $\mathrm{pH}$ on the reduction activity towards ketone substrates, including direct effects on enzyme activity and indirect ones mediated via changes in gene expression and the availability of electron donors. It is reasonable that the conditions that best favor growth are different from those that give highest reduction activity because the two processes may compete for the pool of available electron donors within the cell.
The closer the value of $R^{2}$ is to 1 , the better is the adequacy of the model. In this case, the $R^{2}$ values (0.9856 and 0.9896) indicated that actual values were very close to predicted values and showed that the models were reliable for predicting biomass and reduction activity, respectively, of Acetobacter sp. CCTCC M209061. The "Lack of Fit $F$-value" which were 1.89 ( $P$ value $0.25>0.05)$ and $0.24(P$-value $0.97>0.05)$ also implied that the predicted values exhibit a good correlation with the experimental data. Hence, all of the parameters indicated that the model was adequate for prediction.

Three-dimensional response surface plots and corresponding contour plots were constructed to show the effects of the conditions on growth (Figure 2) and reduction activity (Figure 3) of Acetobacter sp. CCTCC M209061. The effects of independent variables are shown in pairs within the experimental range, while the other two variables in each case are fixed at center point levels. This kind of graphical visualization allows the relationships between the experimental levels of each factor and the response to be investigated, and the type of interactions between test variables to be determined, which is necessary to establish the optimal medium components and culture conditions. The elliptical nature of the curves indicates significant mutual interactions between variables, in contrast to the circular shapes of the contour plots. There was a large interactive effect of glucose and soy peptone on growth of 

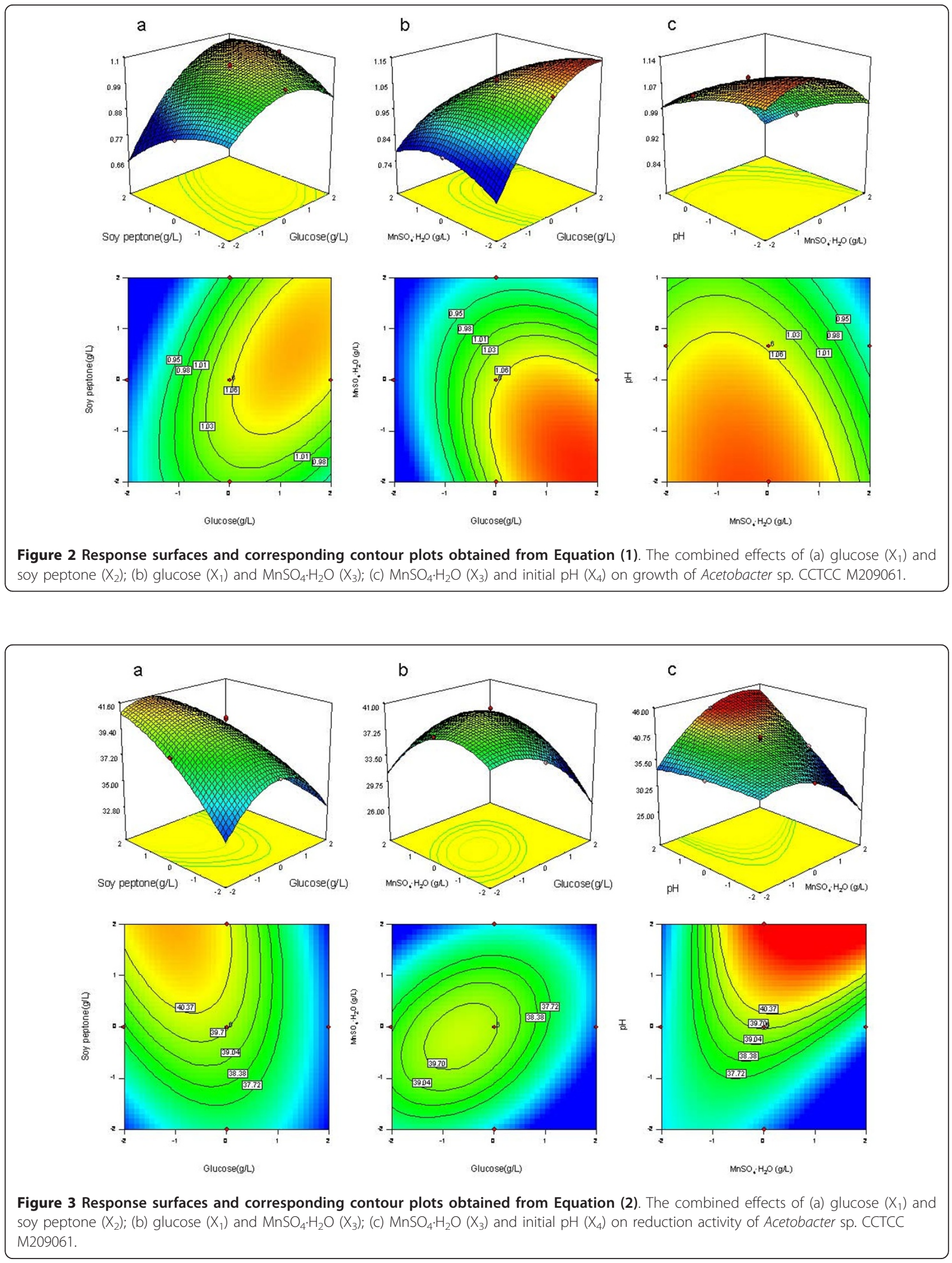
Acetobacter sp. CCTCC M209061 (Figure 2a). At low to moderate glucose concentration, the biomass increased marginally with the increase of soy peptone concentration, but at high glucose concentration, increase in soy peptone concentration led to much greater increase of biomass. Substantial interaction was also observed between the effects on cell growth of the other pairs of variables shown, namely $\mathrm{MnSO}_{4} \cdot \mathrm{H}_{2} \mathrm{O}$ and $\mathrm{pH}$ (Figure 2b) and glucose and $\mathrm{MnSO}_{4} \cdot \mathrm{H}_{2} \mathrm{O}$ (Figure 2c).

When specific activity was considered, the strongest interaction between variables was that between $\mathrm{MnSO}_{4} \cdot \mathrm{H}_{2} \mathrm{O}$ and $\mathrm{pH}$ (Figure $3 \mathrm{~b}$ ), followed by the interaction between glucose and soy peptone (Figure $3 \mathrm{a}$ ) and that between soy peptone and $\mathrm{pH}$ (Figure 3c).

The optimum levels of the factors investigated can be deduced from the 3D and 2D response surface plots and the equations obtained from multiple regression analysis. The model predicted that the maximum cell growth $(1.17 \mathrm{~g} / \mathrm{L})$ was located at $\mathrm{X}_{1}=11.89 \mathrm{~g} / \mathrm{L}, \mathrm{X}_{2}=87.44 \mathrm{~g} /$ $\mathrm{L}, \mathrm{X}_{3}=0.076 \mathrm{~g} / \mathrm{L}$, and $\mathrm{X}_{4}=4.62$. Likewise, the predicted specific activity $(45.34 \mu \mathrm{mol} / \mathrm{min} / \mathrm{g})$ reached its maximum at the values: $X_{1}=7.07 \mathrm{~g} / \mathrm{L}, X_{2}=87.16 \mathrm{~g} / \mathrm{L}, X_{3}=$ $0.10 \mathrm{~g} / \mathrm{L}$, and $\mathrm{X}_{4}=6.5$. The predicted levels of factors to maximize biomass were rather different from those predicted to maximize the specific reduction activity. Although specific activity requires moderate concentration of glucose and relative high $\mathrm{pH}$, maximal biomass was achieved in the presence of a relative high concentration of glucose and low $\mathrm{pH}$. For instance, in the nutrient medium needed for maximal specific activity $(45.34 \mu \mathrm{mol} / \mathrm{min} / \mathrm{g})$, the predicted biomass was $0.82 \mathrm{~g} / \mathrm{L}$, which was not satisfactory for practical applications. Thus, numerical optimization of the overall desirability function was performed to determine the best possible goals for each response simultaneously. The predicted optimal values for the variables were as follows: $\mathrm{X}_{1}=$ $8.26 \mathrm{~g} / \mathrm{L}, \mathrm{X}_{2}=83.92 \mathrm{~g} / \mathrm{L}, \mathrm{X}_{3}=0.088 \mathrm{~g} / \mathrm{L}$, and $\mathrm{X}_{4}=5.70$, and the predicted responses were: biomass, $1.05 \mathrm{~g} / \mathrm{L}$; specific activity $40.37 \mu \mathrm{mol} / \mathrm{min} / \mathrm{g}$.

To examine the validity of this model, nine successive experiments were performed in the predicted optimal medium. The average biomass $(1.10 \pm 0.03 \mathrm{~g} / \mathrm{L})$ and specific activity $(39.49 \pm 0.96 \mu \mathrm{mol} / \mathrm{min} / \mathrm{g})$ were very close to the predicted values and strongly support the suitability of the CCRD model developed in this study for improving the reaction.

\section{Comparison of cell growth and reduction activity of the strain in the improved and original basic media}

The improved (optimized) medium described in the previous section was compared for growth and reduction activity of Acetobacter sp. CCTCC M209061 to the original basic medium used at the start of the study (Figure 4). Cells cultured in the improved medium had longer logarithmic phase and reached the maximum of $1.10 \pm$ $0.03 \mathrm{~g} / \mathrm{L} \mathrm{DCW}$ at $30 \mathrm{~h}$. The biomass yield was 9.5 times higher than that from the basic medium. Reduction activity reached $39.49 \pm 0.96 \mu \mathrm{mol} / \mathrm{min} / \mathrm{g}$ in the improved medium, which was 1.33 -fold higher than that in basic medium $(29.34 \pm 0.65 \mu \mathrm{mol} / \mathrm{min} / \mathrm{g})$. Hence, the optimization described in this study increased the reduction activity per litre of culture by more than 12 -fold. The reduction activity declined sharply after reaching its maximum value in basic medium, however, in the improved medium cells maintained near-maximum activity between 12 and $36 \mathrm{~h}$ after inoculation. The reason for the improved stability of the activity may be that the presence of added manganese allows the reduction activity to be maintained for longer. The carbon source conversion in the improved medium was higher than in the basic medium (Figure 4c), which was consistent with the biomass yield results and suggested that a greater amount of carbon source was available for growth and reduction activity by Acetobacter sp. CCTCC M209061 in the improved medium. As shown in Figure $4 \mathrm{~d}$, the $\mathrm{pH}$ decreased during cultivation in both media, but fell significantly more in the improved medium.

\section{Performance of the optimized biocatalyst for enantioselective reduction of 4-(trimethylsilyl)-3-butyn-2- one}

Whilst the increase in biocatalyst biomass due to the optimization of the culture medium would benefit any reduction reaction catalyzed by Acetobacter sp. CCTCC M209061, it was possible that the change in culture conditions might affect the rate of reduction of different substrates to different extents. The cells cultured in the improved medium were therefore tested as the biocatalyst for the key enantioselective reduction of 4-(trimethylsilyl)-3-butyn-2-one to $(R)$ - 4-(trimethylsilyl)-3butyn-2-ol that we investigated previously [10]. Compared with the previous work, using cells prepared from the optimized reaction medium, under the reduction reaction conditions described previously, the initial reaction rate increased from $0.5 \mu \mathrm{mol} / \mathrm{min}$ to $1.13 \mu \mathrm{mol} /$ min; the yield was enhanced from $71 \%$ to $83 \%$ and the product e.e. was $>99 \%$ after a reaction time of $40 \mathrm{~min}$. Hence the combined effects of increased biocatalyst biomass and increased yield would afford an extensive increase in the productivity of this reaction, which was comparable to the improvement achieved with the model reduction reaction used for the optimization. These results also represented an enantiocomplementary transformation to the reduction of 4-(trimethylsilyl)-3butyn-2-one to $(S)$ - 4-(trimethylsilyl)-3-butyn-2-ol catalysed by immobilized Candida parapsilosis CCTCC M203011 cells in an ionic liquid system [29]. 

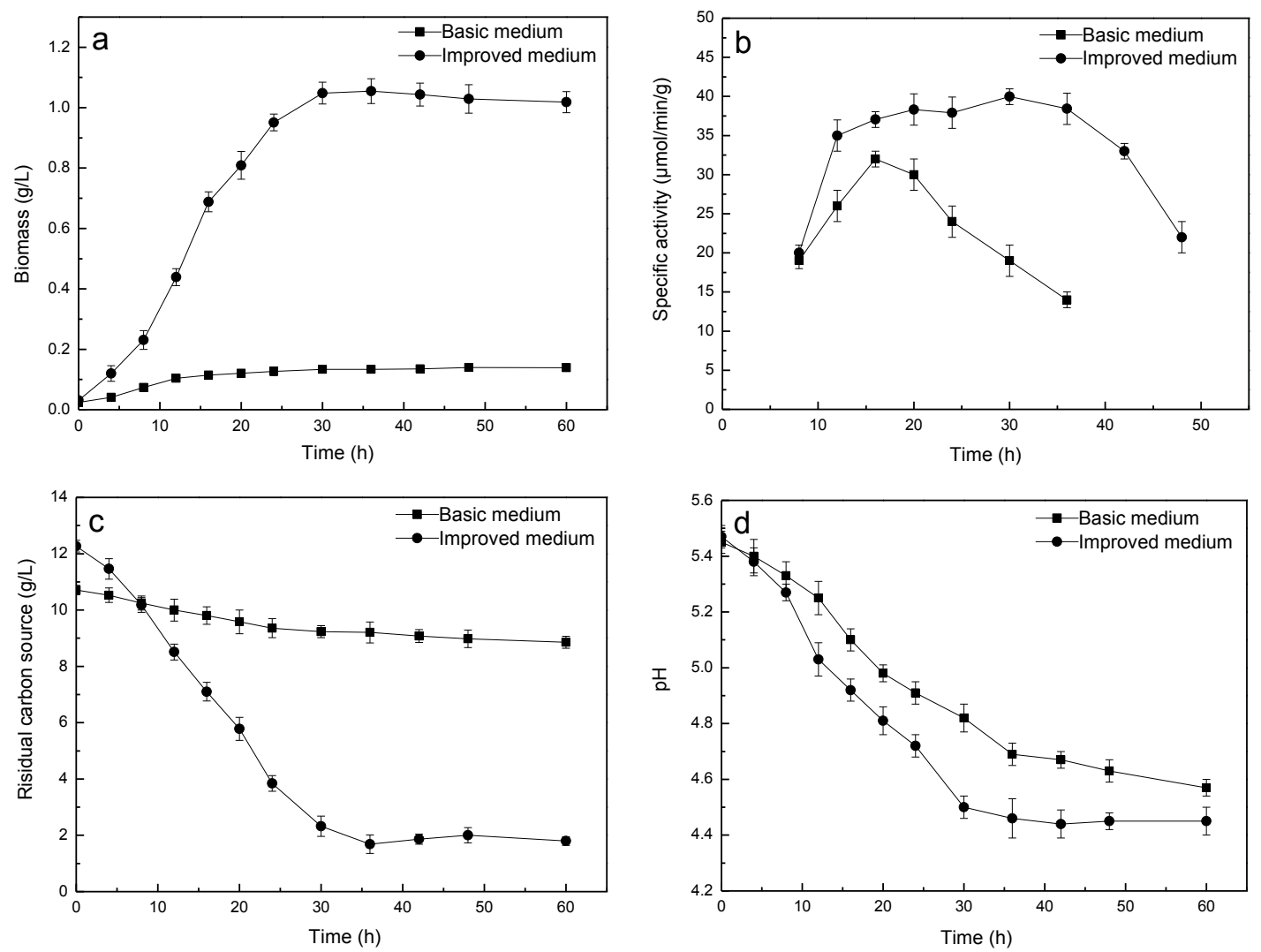

Figure 4 Comparison of growth and reduction activity of Acetobacter sp. CCTCC M209061 in various medium.

\section{Conclusions}

Cultivation conditions were optimized for Acetobacter sp. CCTCC M209061, which acted as an anti-Prelog specific whole cell biocatalysts for reduction of prochiral ketones. Using a classical one-factor-at-one-time method followed by a response surface methodology, culture conditions were optimized to obtain simultaneously high yields of biomass $(1.10 \mathrm{~g} / \mathrm{L})$ and high reduction activity $(39.49 \mu \mathrm{mol} / \mathrm{min} / \mathrm{g}$ with the model substrate 4'chloroacetophenone). These results, which gave a more than 12 -fold improvement in the yield of reduction activity per litre of culture, were expected to facilitate use of Acetobacter sp. CCTCC M209061 cells in the production of chiral alcohols as building blocks for many industries.

\section{Methods}

\section{Biological and chemical materials}

The new strain, Acetobacter sp. CCTCC M209061, was isolated previously from Chinese kefir grains and kept in our laboratory [10].

4'-Chloroacetophenone (97\% purity), (R)-1-(4-chlorophenyl) ethanol (> 95\% purity), 1-(4-chlorophenyl) ethanol (> 98\% purity), 3'-methoxyacetophenone (97\% purity), 4-(trimethylsilyl)-3-butyn-2-one (97\% purity), 4(tri-methylsilyl)-3-butyn-2-ol (97\% purity) and n-decane (> 99\% purity) were purchased from Sigma-Aldrich (USA). All other chemicals were from commercial sources and were of analytical grade.

\section{Cultivation of Acetobacter sp. CCTCC M209061}

Seed medium (tomato juice medium) consisted of $10 \mathrm{~g} /$ $\mathrm{L}$ glucose, $10 \mathrm{~g} / \mathrm{L}$ peptone, $10 \mathrm{~g} / \mathrm{L}$ yeast extract, $20 \%$ (v/ v) tomato juice and was adjusted to $\mathrm{pH} 6.0$ [10]. Basic medium, which was used as the starting point for optimization of the culture conditions, contained $10 \mathrm{~g} / \mathrm{L}$ glucose as the carbon source, $10 \mathrm{~g} / \mathrm{L}$ peptone and $10 \mathrm{~g} /$ $\mathrm{L}$ yeast extract as the nitrogen source, and a mineral element component in the form of $2 \mathrm{~g} / \mathrm{L}$ of $\mathrm{K}_{2} \mathrm{HPO}_{4}$; $\mathrm{pH}$ was adjusted to 6.0. The media were sterilized by autoclaving at $121^{\circ} \mathrm{C}$ for $20 \mathrm{~min}$.

Initial cultivation of Acetobacter sp. CCTCC M209061 was performed in $250 \mathrm{~mL}$ Erlenmeyer flasks containing $45 \mathrm{~mL}$ of basic medium, which was inoculated by adding $5 \mathrm{~mL}$ of starter culture in tomato juice medium for $13 \mathrm{~h}$ cultivation. The culture was grown at $30^{\circ} \mathrm{C}$ and a shaking rate of $120 \mathrm{rpm}$. Wet cells were harvested at the late exponential growth phase $\left(20 \mathrm{~h}\right.$ without $\mathrm{Mn}^{2+}$ 
and $30 \mathrm{~h}$ with $\left.\mathrm{Mn}^{2+}\right)$ by centrifugation $\left(4^{\circ} \mathrm{C}, 8000 \mathrm{rpm}\right.$ for $10 \mathrm{~min}$ ), washed twice with TEA-HCl buffer (100 $\mathrm{mmol} / \mathrm{L}, \mathrm{pH}$ 5.0) and used for the reduction activity assay.

\section{Dry cell weight (DCW) determination}

Fermentation samples $(50 \mathrm{~mL})$ were centrifuged $(8,000$ $\mathrm{rpm}$ ) for $10 \mathrm{~min}$ at $4^{\circ} \mathrm{C}$. The wet cells from the samples were washed twice with distilled water and dried $\left(105^{\circ} \mathrm{C}\right.$, $24 \mathrm{~h}$ ) to a constant mass. The biomass was expressed as dry cell weight per liter of culture medium; the values given are averages of experiments conducted at least in triplicate. A calibration curve (dry cell weight, g vs. OD at $420 \mathrm{~nm}, R^{2}=0.9987$ ) was established with experiments. Cell growth was determined by measuring optical density at $420 \mathrm{~nm}$ which was then converted to DCW.

\section{Residual carbon source determination}

The residual carbon source concentration was detected using a 3, 5-dinitrosalicylic (DNS) acid method [30].

\section{Reduction activity assay}

4'-Chloroacetophenone reduction was employed as a model reaction for assaying the reduction activity of Acetobacter sp. CCTCC M209061. In a typical experiment, $2.0 \mathrm{~mL}$ of TEA-HCl buffer $(100 \mathrm{mmol} / \mathrm{L}, \mathrm{pH} 5.0)$ containing $130.6 \mathrm{mmol} / \mathrm{L}$ of isopropyl alcohol (the source of reducing equivalents) and $5.0 \mathrm{mmol} / \mathrm{L}$ of 4 'chloroacetophenone were added to a $10-\mathrm{mL}$ Erlenmeyer flask capped with a septum, and pre-incubated in a water-bath shaker at $30^{\circ} \mathrm{C}$ and $160 \mathrm{rpm}$ for $10 \mathrm{~min}$. Then, the bioreduction reaction was initiated by adding the harvested wet cells to the mixture. Aliquots $(50 \mu \mathrm{L})$ were withdrawn at specified time intervals. The product and the residual substrate were extracted twice with isopropyl ether $(100 \mu \mathrm{L})$ containing $5.0 \mathrm{mM} \mathrm{3}$ '-methoxyacetophenone (internal standard) prior to GC analysis. The specific reduction activity of the cell was defined as the initial reaction rate per gram of DCW.

The reduction of 4-(trimethylsilyl)-3-butyn-2-one was monitored using the method reported previously [10].

\section{GC analysis}

In the case of 4'-chloroacetophenone reduction, reaction mixtures were assayed with a GC 2010 gas chromatograph (Shimadzu Corp., Kyoto, Japan) equipped with an HP-Chiral column $(30 \mathrm{~m} \times 0.25 \mathrm{~mm}$, coating thickness $0.25 \mu \mathrm{m}$, J\&W Scientific, USA) and a flame ionization detector. The column temperature was held at $140^{\circ} \mathrm{C}$ for $9 \mathrm{~min}$. Nitrogen was used as the carrier gas at a flow rate of $3 \mathrm{~mL} / \mathrm{min}$. The split ratio was 1:100 (v/v). The injector and the detector temperatures were set at $250^{\circ} \mathrm{C}$ and $250^{\circ} \mathrm{C}$, respectively. The retention times for 4'- chloroacetophenone, 3'-methoxyacetophenone, $(R)$-1-(4chlorophenyl) ethanol and (S)-1-(4-chlorophenyl) ethanol were $4.736 \mathrm{~min}, 6.197 \mathrm{~min}, 7.596 \mathrm{~min}$ and 8.021 min, respectively. The average error for this determination was less than $1 \%$. All reported data were averages of experiments performed at least in duplicate.

For 4-(trimethylsilyl)-3-butyn-2-one reduction, the reaction mixtures were assayed according to the chiral GC analysis method reported previously [31].

\section{Effect of medium components and culture conditions using the one-factor-at-a-time method}

To determine the most important medium components and culture conditions for the growth and reduction activity of Acetobacter sp. CCTCC M209061, medium and culture parameters were varied singly. The parameters explored were type of carbon source (glucose, fructose, galactose, arabinose, ribose, xylose, lactose or sucrose; each at a concentration of $10 \mathrm{~g} / \mathrm{L}$ ), nitrogen source (peptone, yeast extract, ammonium sulfate or urea; each at a total nitrogen concentration of $2.15 \mathrm{~g} / \mathrm{L}$ ), mineral element $\left(\mathrm{K}_{2} \mathrm{HPO}_{4}, \mathrm{MgSO}_{4} \cdot 7 \mathrm{H}_{2} \mathrm{O}, \mathrm{CaCl}_{2}\right.$, $\mathrm{ZnSO}_{4} \cdot 7 \mathrm{H}_{2} \mathrm{O}, \mathrm{MnSO}_{4} \cdot \mathrm{H}_{2} \mathrm{O}, \mathrm{FeSO}_{4}$ or $\mathrm{CuSO}_{4} \cdot 5 \mathrm{H}_{2} \mathrm{O}$; each at different concentrations, as detailed in the Results), vitamins (thiamine, nicotinic acid, pyridoxine, ascorbic acid or biotin, each at a concentration of $2 \mathrm{mg} /$ $\mathrm{L}$ ), and various physical conditions (initial $\mathrm{pH}$, temperature and shaking rate). Samples were withdrawn from each culture at specified time intervals for estimation of biomass via $\mathrm{OD}_{420 \mathrm{~nm}}$ and the harvested wet cells were used for reduction activity assays. During the one-factor-at-a-time optimization, the factors (carbon source, nitrogen source, mineral elements, vitamins, $\mathrm{pH}$, temperature and shaking rate) were optimized sequentially in the order described in the Results (sections 3.1-3.6) and the optimized value for each factor was used in subsequent stages of the optimization.

\section{Optimization of medium components and culture conditions by response surface methodology}

As detailed in the Results section, the above one-variable-at-a-time method gave the highest biomass and activity in the presence of glucose, soy peptone, and $\mathrm{MnSO}_{4} \cdot \mathrm{H}_{2} \mathrm{O}$, and indicated that the initial $\mathrm{pH}$ was important also. The response surface methodology (RSM) was then used to optimize the quantitative concentrations and levels of these variables. The experimental design was performed by using the software Design Expert 7 (Stat-Ease, Minneapolis, MN, USA). A full $2^{4}$ factorial central composite rotatable design (CCRD) that contained six replications at the central points $\left(n_{0}=6\right)$ was performed, which meant that a total of 30 experiments were required. The levels of each factor tested in the CCRD experiment are shown in Table 3. Biomass 
and reduction activity for each shake-flask run were determined after a fermentation period of $30 \mathrm{~h}$, and the observed values were affected by the individual factors and their interactions. The actual concentrations of each medium component were coded to facilitate multiple regression analysis. The second-order polynomial model used to simulate experimental data give the equation:

$$
Y_{i}=\beta_{0}+\sum_{i=1}^{k} \beta_{i} X_{i}+\sum_{i=1}^{k} \beta_{i i} X_{i}^{2}+\sum_{i<j}^{k} \sum \beta_{i j} X_{i} X_{j}
$$

where $Y_{\mathrm{i}}$ is the predicted response, subscripts $\mathrm{i}$ and $\mathrm{j}$ take values from 1 to $4, \beta_{0}$ is a constant, $\beta_{\mathrm{i}}$ is the linear coefficient, $\beta_{\mathrm{ii}}$ is the quadratic coefficient, $\beta_{\mathrm{ij}}$ is the crossproduct coefficient, $k$ is the number of factors (which was 4 in this study), $X_{\mathrm{i}}$ and $X_{\mathrm{j}}$ are the coded dimensionless values of the investigated variables that influence the response variable $Y_{\mathrm{i}}$. The analysis of variance (ANOVA) and the graphical analysis of the data were also performed by using the software Design Expert 7 (Stat-Ease, Minneapolis, MN, USA). The statistical significance of the quadratic model was assessed using an $F$-test, and the quality of fit was evaluated by $R^{2}$. The significances of the regression coefficients were tested by a t-test, and the $P$-values were used as a tool to check the significance of each coefficient. The optimal levels of the investigated factors needed for simultaneous maximization of two responses (biomass and reduction activity) were established using the overall desirability function, which is the geometric mean of the individual desirability [15].

\begin{abstract}
Acknowledgements
We would like to thank the National Natural Science Foundation of China (Grant No. 21072065; 20876059), the Fundamental Research Funds for the Central Universities - SCUT (Grants No. 2011ZG0018; 2009ZZ0026), the Foundation for the Author of National Excellent Doctoral Dissertation of China (Grants No. 201504), the New Century Excellent Talents in University (Grant No. NCET-10-0367), the Ph.D. Programs Foundation of Ministry of Education of China (Grant No. 20090172110019) and the National Program on Key Basic Research Project (Grant No. 2010CB732201) for partially funding this work.

\section{Author details \\ ${ }^{1}$ Lab of Applied Biocatalysis, South China University of Technology, Guangzhou, 510640, China. ${ }^{2}$ College of Light Industry and Food Sciences, South China University of Technology, Guangzhou, 510640, China. ${ }^{3}$ Biomedical Research Centre, Sheffield Hallam University, Owen Building, Howard Street, Sheffield, S1 1WB, UK.}

\section{Authors' contributions}

WYL and MHZ participated in the design of the study; XHC carried out experiments and wrote the draft of manuscript; TJS assisted with data interpretation and revision of the manuscript. All authors read and approved the final manuscript

Received: 22 July 2011 Accepted: 20 November 2011 Published: 20 November 2011

\section{References}

1. Kanchanarach W, Theeragool G, Yakushi T, Toyama H, Adachi O, Matsushita K: Characterization of thermotolerant Acetobacter pasteurianus strains and their quinoprotein alcohol dehydrogenases. App/ Microbiol Biotechnol 2010, 85:741-751.

2. Vegas C, Mateo E, Gonzalez A, Jara C, Guillamon JM, Poblet M, Torija MJ, Mas A: Population dynamics of acetic acid bacteria during traditional wine vinegar production. Int J Food Microbiol 2010, 138:130-136.

3. Kurosumi A, Sasaki C, Yamashita Y, Nakamura Y: Utilization of various fruit juices as carbon source for production of bacterial cellulose by Acetobacter xylinum NBRC 13693. Carbohydrate Polymers 2009, 76:333-335.

4. Bäckdahl H, Risberg B, Gatenholm P: Observations on bacterial cellulose tube formation for application as vascular graft. Mater Sci Eng C 2011, 31:14-21.

5. Shah J, Brown RM: Towards electronic paper displays made from microbial cellulose. Appl Microbiol Biotechnol 2005, 66:352-355.

6. Tkac J, Svitel J, Vostiar I, Navratil M, Gemeiner P: Membrane-bound dehydrogenases from Gluconobacter sp.: interfacial electrochemistry and direct bioelectrocatalysis. Bioelectrochemistry 2009, 76:53-62.

7. Gandolfi R, Borrometi A, Romano A, Gago JVS, Molinari F: Enantioselective oxidation of ( \pm )-2-phenyl-1-propanol to (S)-2-phenyl-1-propionic acid with Acetobacter aceti: influence of medium engineering and immobilization. Tetrahedron-Asymmetry 2002, 13:2345-2349.

8. Molinari F, Gandolfi R, Villa R, Urban E, Kiener A: Enantioselective oxidation of prochiral 2-methyl-1, 3-propandiol by Acetobacter pasteurianus. Tetrahedron-Asymmetry 2003, 14:2041-2043.

9. Pini E, Bertacche V, Molinari F, Romano D, Gandolfi R: Direct conversion of polyconjugated compounds into their corresponding carboxylic acids by Acetobacter aceti. Tetrahedron 2008, 64:8638-8641.

10. Xiao ZJ, Zong MH, Lou WY: Highly enantioselective reduction of 4(trimethylsilyl)-3-butyn-2-one to enantiopure (R)-4-(trimethylsilyl)-3butyn-2-ol using a novel strain Acetobacter sp CCTCC M209061. Bioresour Technol 2009, 100:5560-5565.

11. Romano A, Gandolfi R, Nitti P, Rollini M, Molinari F: Acetic acid bacteria as enantioselective biocatalysts. J Mol Catal B: Enzym 2002, 17:235-240.

12. Frebortova J, Matsushita K, Adachi O: Effect of growth substrates on formation of alcohol dehydrogenase in Acetobacter methanolicus and Acetobacter aceti. J Ferment Bioeng 1997, 83:21-25.

13. Wethmar M, Deckwer WD: Semisynthetic culture medium for growth and dihydroxyacetone production by Gluconobacter oxydans. Biotechnol Techniques 1999, 13:283-287.

14. Frey DD, Engelhardt F, Greitzer EM: A role for 'one-factor-at-a-time' experimentation in parameter design. Res Eng Des 2003, 14:65-74.

15. Malinowska E, Krzyczkowski W, Łapienis G, Herold F: Improved simultaneous production of mycelial biomass and polysaccharides by submerged culture of Hericium erinaceum: optimization using a central composite rotatable design (CCRD). J Ind Microbiol Biotechnol 2009, 36:1513-1527.

16. Najafi AR, Rahimpoura MR, Jahanmiri AH, Roostaazad R, Arabian D, Ghobadi Z: Enhancing biosurfactant production from an indigenous strain of Bacillus mycoides by optimizing the growth conditions using a response surface methodology. Chem Eng J 2010, 163:188-194.

17. Oskouie SFG, Tabandeh F, Yakhchali B, Eftekhar F: Response surface optimization of medium composition for alkaline protease production by Bacillus clausii. Biochem Eng J 2008, 39:37-42.

18. Gao H, Liu M, Liu JT, Dai HQ, Zhou XL, Liu XY, Zhuo Y, Zhang WQ, Zhang LX: Medium optimization for the production of avermectin B1a by Streptomyces avermitilis 14-12A using response surface methodology. Bioresour Technol 2009, 100:4012-4016.

19. Daniel RM, Erickson SK: The effect of glucose on the electron-transport systems of the aerobic baceria Azotobacter vinelandii and Acetobacter suboxydans. Biochim Biophys Acta Bioenerg 1969, 180:63-67.

20. Luo Y, Chen GX: Combined approach of NMR and chemometrics for screening peptones used in the cell culture medium for the production of a recombinant therapeutic protein. Biotechnol Bioeng 2007, 97:1654-1659.

21. Cai CG, Zheng XD: Medium optimization for keratinase production in hair substrate by a new Bacillus subtilis KD-N2 using response surface methodology. J Ind Microbiol Biotechnol 2009, 36:875-883.

22. Kumari M, Survase SA, Singhal RS: Production of schizophyllan using Schizophyllum commune NRCM. Bioresour Technol 2008, 99:1036-1043.

23. Revankar MS, Lele SS: Enhanced production of laccase using a new isolate of white rot fungus WR-1. Process Biochem 2006, 41:581-588. 
24. Stamer JR, Albury MN, Pederson CS: Substitution of manganese for Tomato Juice in the cultivation of Lactic Acid Bacteria. Appl Environ Microbiol 1964, 12:165-168.

25. Leskovac V, Trivic S, Pericin D: The three zinc-containing alcohol dehydrogenase from baker's yeast Saccharomyces cerevisiae. FEMS Yeast Res 2002, 2:481-494.

26. Lin ES, Sung SC: Cultivating conditions influence exopolysaccharide production by the edible basidiomycete Antrodia cinnamomea in submerged culture. Int J Food Microbiol 2006, 108:182-187.

27. Kim HO, Lim JM, Joo JH, Kim SW, Hwang HJ, Choi JW, Yun JW: Optimization of submerged culture condition for the production of mycelial biomass and exopolysaccharides by Agrocybe cylindracea. Bioresour Technol 2005, 96:1175-1182.

28. Menzel U, Gottschalk $\mathrm{G}$ : The internal pH of Acetobacterium wieringae and Acetobacter aceti during growth and production of acetic acid. Arch Microbiol 1985, 143:47-51.

29. Lou WY, Chen L, Zhang BB, Smith TJ, Zong MH: Using a water-immiscible ionic liquid to improve asymmetric reduction of 4-(trimethylsilyl)-3butyn-2-one catalyzed by immobilized Candida parapsilosis CCTCC M203011 cells. BMC Biotechnology 2009, 9:90.

30. Miller GL: Use of dinitrosalycilic acid reagent for determination of reducing sugars. Anal Chem 1959, 31:426-428.

31. Zhang BB, Lou WY, Zong MH, Wu H: Efficient synthesis of enantiopure (S)-4-(trimethylsilyl)-3-butyn-2-ol via asymmetric reduction of 4(trimethylsilyl)-3-butyn-2-one with immobilized Candida parapsilosis CCTCCM203011 cells. J Mol Catal B: Enzym 2008, 54:122-129.

doi:10.1186/1472-6750-11-110

Cite this article as: Chen et al: Optimization of culture conditions to produce high yields of active Acetobacter sp. CCTCC M209061 cells for anti-Prelog reduction of prochiral ketones. BMC Biotechnology 2011 11:110.

\section{Submit your next manuscript to BioMed Central and take full advantage of:}

- Convenient online submission

- Thorough peer review

- No space constraints or color figure charges

- Immediate publication on acceptance

- Inclusion in PubMed, CAS, Scopus and Google Scholar

- Research which is freely available for redistribution

Submit your manuscript at www.biomedcentral.com/submit 